\title{
A Community Based Epidemiological and Clinical Study of Hospitalization of Patients With Congestive Heart Failure in Northern Iwate, Japan
}

\author{
Muneyoshi Ogawa, MD; Fumitaka Tanaka, MD; Toshiyuki Onoda, MD*; \\ Masaki Ohsawa, MD*; Kazuyoshi Itai, PhD*; Toshiaki Sakai, MD**; \\ Akira Okayama, MD***; Motoyuki Nakamura, MD On Behalf of \\ the Northern Iwate Heart Disease Registry Consortium
}

\begin{abstract}
Background Community based studies of congestive heart failure (HF) are lacking in the Japanese population. Methods and Results To delineate the epidemiological and clinical features of advanced HF in the general Japanese population, hospitalized adult cases of HF in all hospitals within the Ninohe district were registered for 3 years. During the survey period, 190 new onset cases (males $n=93$; females $n=97$ ) and a total of 391 hospitalizations (including repeat admissions) were registered. The prevalence of atrial fibrillation in new HF cases was 56\% in males and $45 \%$ in females. On the basis of the population of the district, the incidence of hospitalized HF was 96 in males and 92 in females per 100,000 person-years. The percentage of HF patients who were $\geq 65$ years of age was $82 \%$ in males and $94 \%$ in females. In cases undergoing echocardiography, preserved left ventricular systolic function (left ventricular ejection fraction $\geq 50 \%$ ) was observed in $29 \%$ of males and $41 \%$ of females. There was a significant seasonal variation in HF admissions (Spring 32\%; Summer 20\%; Autumn 20\%; Winter 28\%; p $<0.01$ ). Conclusions In comparison with published results of USA and European community based studies of HF, the present HF cohort showed that: (1) mean age, prevalence of preserved ejection fraction, and trends in seasonal variation were comparable; however (2) the incidence of HF was obviously lower. These epidemiological and clinical characteristics should be taken into consideration when establishing a therapeutic and preventive approach for HF. (Circ J 2007; 71: 455-459)
\end{abstract}

Key Words: Community; Epidemiology; Heart failure; Incidence; Population; Prevalence

C ongestive heart failure (HF) is one of the most common reasons for hospital admission among the elderly in US and European populations 1,2 This increase in prevalence might be caused by rising mean age and improved survival of patients with cardiovascular disease because of therapeutic advances 3,4 Moreover, patients with $\mathrm{HF}$ are at high risk of readmission to hospital. In fact, surveys in the USA and Europe have reported that 16-50\% of elderly HF patients are readmitted within 6 months of their first admission, ${ }^{2,-7}$ As a consequence, HF has become an important public health problem, with increasing prevalence placing a growing burden on health-care systems in these countries?

The mean age of the Japanese population is increasing steeply and it is estimated that by the year $202025 \%$ of the population will be $\geq 65$ years of age. As observed in the USA and Europe, the HF epidemic might become evident in our population. However, there has been a deficiency of population or community based epidemiological studies in the Japanese population to date, leaving a gap in epidemio-

(Received October 10, 2006; revised manuscript received December 4, 2006; accepted December 21, 2006)

Second Department of Internal Medicine, *Hygiene and Preventive Medicine, Iwate Medical University, Morioka, **Iwate Prefecture Ninohe Hospital, Ninohe and ***National Cardiovascular Center, Suita, Japan

Mailing address: Motoyuki Nakamura, MD, Second Department of Internal Medicine, Iwate Medical University, 19-1 Uchimaru, Morioka 020-8505, Japan. E-mail: nkmrmoto@iwate-med.ac.jp logical data such as incidence, prevalence and prognosis of $\mathrm{HF}$ in this country. These data are not simply a matter of curiosity but will be essential for physicians, policy makers, economists, health-care administrators, and pharmaceutical manufacturers.

Although several epidemiological and clinical studies of $\mathrm{HF}$ in teaching hospitals have been published or are ongoing in this country9 no adequate community based data have been reported. We have therefore collected prospective data on all registered hospitalized adult patients with HF over a 3-year period in the Ninohe district, a rural community in northern Iwate where medical facilities are limited and the population is relatively stable. On the basis of this registration survey, we have calculated hospitalization and readmission rates, seasonal variations, and the incidence of preserved left ventricular systolic function and atrial fibrillation in HF patients.

\section{Methods}

\section{Study Population}

The Ninohe district is a rural area situated in the Iwate prefecture, northeast of Honsyu, Japan (Fig 1). The Ninohe district comprises the city of Ninohe, the towns of Ichinohe, Karumai and Jouboji, and the village of Kunohe. According to annual statistical data for 2003 issued by the Iwate prefecture government, this region had a resident population of 67,307 (32,257 males; 35,050 females). The percentage of the population aged $\geq 65$ years was $26 \%$. Following an in- 


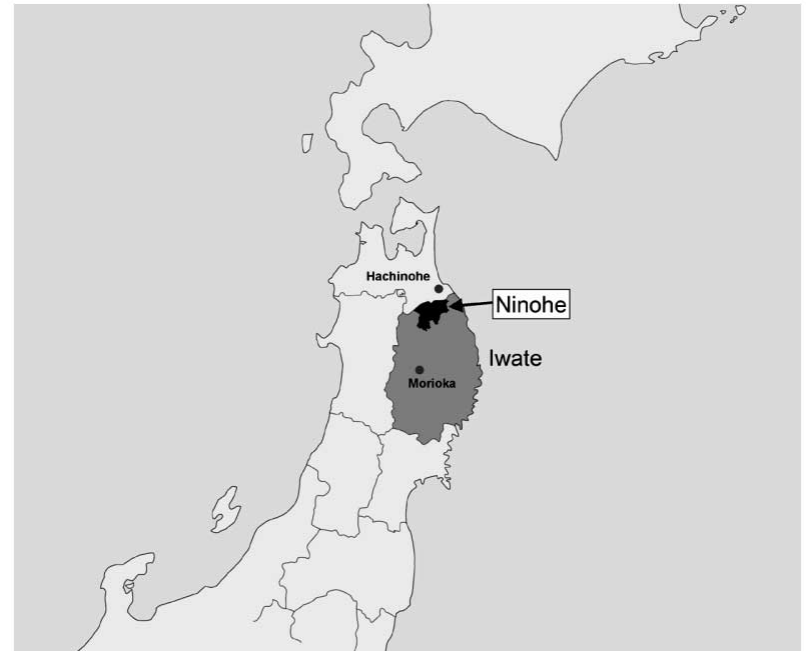

Fig 1. Study area. Ninohe district of Iwate, northern Honsyu, Japan.

tensive briefing on the rationale for the study and discussion of ethical issues, physicians representing all primary care and referral centers in the Ninohe district community agreed to participate. The district contains only 4 public hospitals (Ninohe, Ichinohe, Karumai and Ibonai Hospitals) and 7 private clinics with admission facilities. In addition, to ensure almost complete capture of all HF hospitalizations within the Ninohe district during the study period, registration was extended to include medical centers located in Morioka city ( $60 \mathrm{~km}$ south of Ninohe) including our University hospital and 3 referral medical centers located in Hachinohe city (50 km north of Ninohe). Approval was obtained from the ethics review board of each participating hospital prior to commencement of the study. Because the study protocol involved a review of charts obtained as part of routine medical care only, patient consent was not required.

\section{Inclusion Criteria and Enrolment}

Inclusion criteria were based on the Framingham definition of $\mathrm{HF}^{10}$ with subjects assigned a diagnosis of HF if either 2 major criteria or 1 major and 2 minor criteria were present concurrently. The major criteria were: paroxysmal nocturnal dyspnea, orthopnea, abnormal jugular venous distention, rales, cardiomegaly, pulmonary edema, presence of a third heart sound, elevated central venous pressure, and weight loss of $4.5 \mathrm{~kg}$ or more in 5 days. The minor criteria included: edema, night cough, dyspnea on exertion, hepatomegaly, pleural effusion, tachycardia, and weight loss of $4.5 \mathrm{~kg}$ or more in 5 days.

Subjects were enrolled only if they had been hospitalized and fulfilled the following conditions: (1) were established residents of the Ninohe district; (2) were aged $\geq 20$ years; and (3) were admitted between 1 April 2002 and 31 March 2005. Registration was initially performed by attending physicians at each hospital. Patients compatible with the diagnosis of $\mathrm{HF}$ in terms of symptoms, physical examination, chest X-rays, and response to treatment were checked by using a registration card after admission. Patients were excluded if they had been hospitalized: (1) to undergo invasive cardiac examination such as cardiac catheterization; (2) for the introduction of $\beta$-blocker therapy; (3) with an advanced stage malignant tumor and/or preceding apparent pneumonia; (4) within 4 weeks after onset of acute myocar-
Table 1 Comparison of Clinical Characteristics of Patients With Heart Failure Divided by Sex

\begin{tabular}{|c|c|c|c|}
\hline & Male & Female & All \\
\hline \multicolumn{4}{|l|}{ No. (n) } \\
\hline New onset & 93 & 97 & 190 \\
\hline Readmission & 99 & 102 & 201 \\
\hline Total & 192 & 199 & 391 \\
\hline \multicolumn{4}{|l|}{ Mean age (years) } \\
\hline New onset & $73.2 \pm 12.7$ & $80.1 \pm 11.4$ & $76.3 \pm 13.3$ \\
\hline Readmission & $78.6 \pm 10.4$ & $82.0 \pm 9.7$ & $79.9 \pm 10.7$ \\
\hline Total & $75.3 \pm 12.2$ & $81.0 \pm 10.7$ & $78.1 \pm 12.3$ \\
\hline \multicolumn{4}{|c|}{$\%$ of age $\geq 65$ years } \\
\hline New onset & 74 & 92 & 83 \\
\hline Readmission & 90 & 95 & 92 \\
\hline Total & 82 & 94 & 88 \\
\hline \multicolumn{4}{|c|}{$\%$ of age $\geq 80$ years } \\
\hline New onset & 32 & 63 & 48 \\
\hline Readmission & 56 & 65 & 60 \\
\hline Total & 42 & 64 & 53 \\
\hline \multicolumn{4}{|c|}{$\%$ of atrial fibrillation } \\
\hline New onset & 56 & 45 & 50 \\
\hline Readmission & 44 & 37 & 40 \\
\hline Total & 53 & 44 & 48 \\
\hline \multicolumn{4}{|c|}{$\%$ of ejection fraction $\geq 50 \%$} \\
\hline New onset & 26 & 40 & 33 \\
\hline Readmission & 33 & 46 & 32 \\
\hline Total & 29 & 41 & 34 \\
\hline
\end{tabular}

dial infarction; or (5) with end-stage renal failure and without apparent cardiac dysfunction.

To ensure that nearly all appropriate cases had been identified, we periodically retrieved and reviewed medical charts and/or discharge summaries for nearly all patients ( $>99 \%)$ admitted to the cardiology and internal medicine wards of all hospitals within the study district. This was carried out by 2 or more members of the study steering committee, which comprised 3 cardiologists, 3 trained research nurses, and 2 epidemiologists. Patients who had been transferred to another hospital were counted on the index admission only. Echocardiographic evaluation such as left ventricular ejection fraction assessment (Simpson or Teichholtz method) was performed for all patients with HF at 1 hospital (Ninohe Hospital) by full-time attending cardiologists, whereas in the remaining hospitals, evaluation was performed by parttime cardiologists in a small percentage of patients only. The percentage of patients who underwent echocardiographic examination was $65 \%$.

\section{Data Analysis}

Continuous variables are expressed as mean \pm SD. Group comparisons were based on the Student's t-test or chi-square test, as appropriate. Incidence rates were calculated as the observed number of new cases of HF divided by the ageand sex-specific person-years of observation. An estimation of residents in the Ninohe district aged $\geq 20$ years was derived from published census data at October 2003. In addition, the incidence rate was adjusted by using the standard Japanese population. Seasons were defined as follows: Spring $=20$ March to 19 June; Summer=20 June to 21 September; Autumn $=20$ September to 20 December; Winter $=21$ December to 19 March. The significance of seasonal variation was tested by the Roger's method!1 


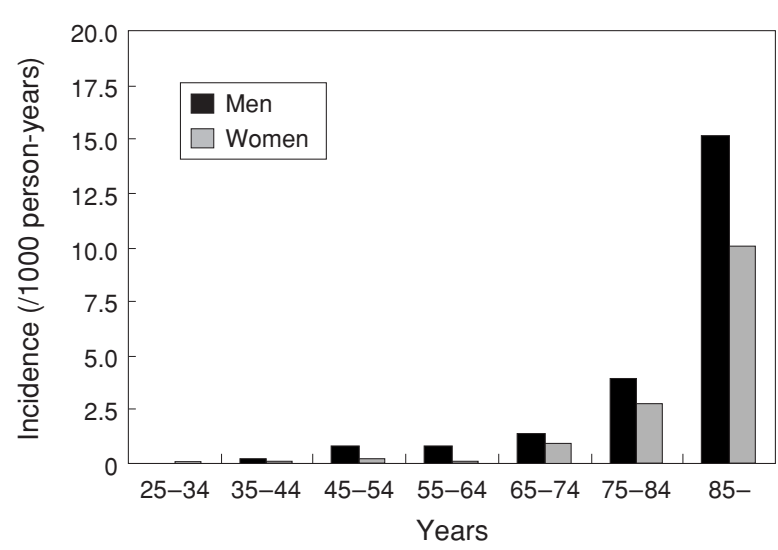

Fig 2. Incidence of heart failure according to the sex and 10-year age group.

\section{Results}

\section{Registered Number of Patients}

During the 3-year study period, the total number of HF patients including readmission cases was 391 (192 males; 199 females). This total included 190 cases of new onset (93 males; 97 females), yielding a readmission case of $51 \%$ in both sexes. There were no significant differences in the number of registered cases by year $(2002, \mathrm{n}=118 ; 2003$, $n=149 ; 2004, n=124:$ NS).

\section{Patient Characteristics}

The age range for new onset cases was 35-96 years in males and 28-98 years in females. As shown in Table 1, the mean age was significantly higher in females $(81.0 \pm$ 10.7 years vs males $75.3 \pm 12.2$ years: $p<0.001)$. Within the new onset cohort, $83 \%$ were $\geq 65$ years of age (74\% males; $92 \%$ females: $\mathrm{p}<0.01$ ), and $48 \%$ were $\geq 80$ years of age (32\% males; $63 \%$ females: $\mathrm{p}<0.01$ ).

\section{Atrial Fibrillation}

Atrial fibrillation was observed in approximately half of new onset cases (Table 1), with no significant difference between the sexes ( $56 \%$ males; $45 \%$ females: NS). Readmission cases showed a comparable trend (44\% males; $37 \%$ females: NS).

\section{Preserved Ejection Fraction}

After exclusion of patients with significant valvular abnormalities, the percentage with a preserved left ventricular ejection fraction of $\geq 50 \%$ was higher in females than in males (41 vs 29\%). Thirty-four percent of registered cases were therefore classified as having HF with preserved ejection fraction. Among the new onset HF cases, the ejection fraction was preserved in $40 \%$ of females and $26 \%$ of males. A similar trend was observed in readmission cases (46\% females, $33 \%$ males). The mean age of patients who underwent echocardiography was significantly younger than that of patients who did not $(76.3 \pm 12.5$ vs $81.7 \pm 10.0$ years of age; $p<0.01)$.

\section{Incidence}

During the 3-year study period, 190 new cases of HF (93 male, 97 female) were diagnosed in the Ninohe district. The crude overall incidence rate was 94 per 100,000 person-years. Male subjects had a slightly higher crude incidence rate at 96 compared to female subjects at 92 per

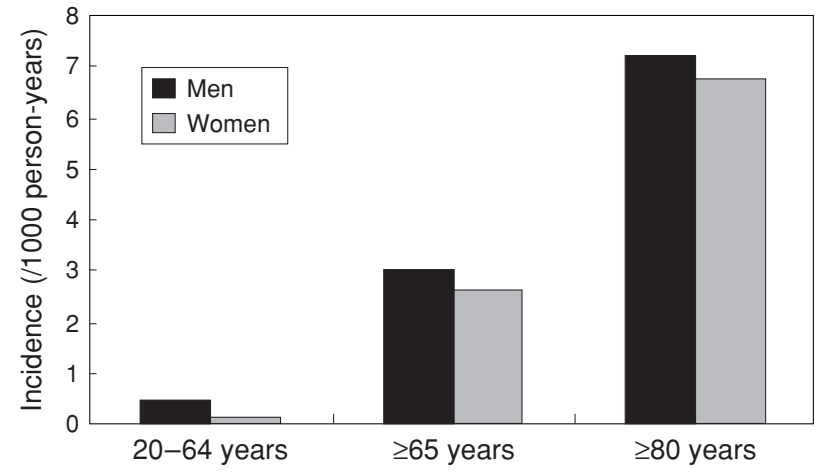

Fig 3. Incidence of heart failure according to sex and age below 65 years, $\geq 65$ years, and $\geq 80$ years.

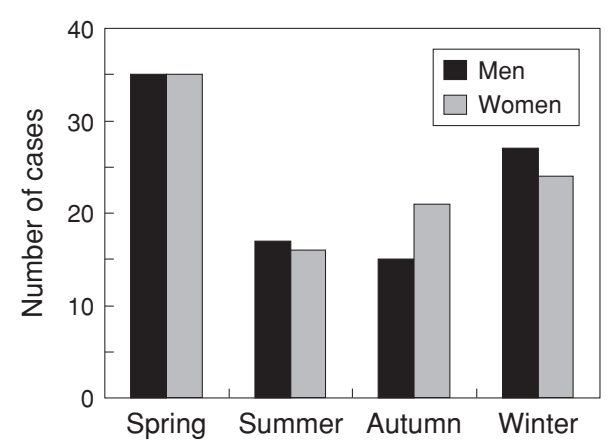

Fig 4. Seasonal variation in the accumulated number of hospitalizations for heart failure during the 3 -year study period.

100,000 person-years. The age- and sex-adjusted incidence rate for the standard Japanese population was 39 per 100,000 person-years. Analysis of incidence rates by age and sex showed a general age-associated increase with male predominance (Fig 2). The incidence rate varied from less than 0.5 per 1,000 person-years in females aged under 65 years to 15 per 1,000 person-years in males aged $\geq 85$ years. As shown in Fig 3, the incidence rates for elderly subjects ( $\geq 65$ years old) were 3.05 per 1,000 person-years for males and 2.65 per 1,000 person-years for females. In the very elderly ( $\geq 80$ years), rates were higher at 7.24 per 1,000 person-years for males and 6.76 per 1,000 personyears for females.

\section{Seasonal Variation}

The cumulative number of new hospitalized cases during the 3-year study period is shown in Fig 4. There was significant variation by season (Spring 37\%; Summer 17\%; Autumn 19\%; Winter 27\%; $\mathrm{p}<0.01)$. Hospitalization rates in Spring and Winter were greater than $50 \%$ higher than in Summer and Autumn. This seasonal variation remained evident when the analysis was performed on all admission cases (including readmissions) (Spring 32\%; Summer $20 \%$; Autumn 20\%; Winter 28\%; $<<0.01$ ).

\section{Discussion}

The present study was conducted in a rural Japanese community where the proportion of the population aged $\geq 65$ years is similar to that predicted for the future Japanese population. We have demonstrated the following new observations: (1) a significant proportion of $\mathrm{HF}$ patients 
were elderly (aged $\geq 65$ years); (2) approximately half of HF cases showed atrial fibrillation at admission; (3) the prevalence of preserved ejection fraction was significantly higher in females than in males; (4) the incidence of HF was less than 100 per 100,000 person-years; and (5) there was seasonal variation with the onset of HF.

The median age of HF cases as a whole was just under 80 years, with a significantly higher mean age in females than in males. This is comparable to reports in other racial populations. ${ }^{12-14}$ Approximately half of the HF patients captured by the present study showed atrial fibrillation at admission. No previous community based study in Japan has reported the prevalence of atrial fibrillation in patients with HF. However, a similar rate has been reported in hospital-based studies ${ }^{15,16}$ There is also evidence of racial variation in the prevalence of atrial fibrillation among patients with HF. Ruo et al have demonstrated that AfricanAmericans had a 50\% lower incidence of atrial fibrillation than Caucasians 17 As incidence rates of atrial fibrillation among Caucasian HF patients have been reported to range from 28 to $42 \%, 18,19$ the prevalence of atrial fibrillation in our patients with HF was somewhat higher than that in other racial populations. However, as atrial fibrillation was prevalent in males and the elderly, ${ }^{20}$ sex- and age-adjusted analysis would be essential to determine the racial difference.

Of patients with HF who underwent echocardiography, half of the female cohort showed preserved ejection fraction while only a quarter of males did so. Although there are no previous reports of the incidence of preserved ejection fraction among HF patients in community based Japanese populations, the present value is comparable to that reported from other ethnic populations using the same partition value for left ventricular ejection fraction.21,22 However, of the potentially eligible patients in the present study, only 65 percent had a documented assessment of left ventricular ejection fraction. This might have resulted in a selection bias. The mean age of patients not undergoing echocardiography was higher than those who did undergo echo examination. As the incidence of preserved ejection fraction is greater in the elderly, this might have been underestimated in the present study.

The incidence of HF in our study community was less than 100 per 100,000 person-years for patients aged 20-65 years. The value rose to approximately 300 per 100,000 person-years in those aged $\geq 65$ years, and approximately 700 per 100,000 person-year in those aged $\geq 80$ years. However, these values are clearly lower than that of published data from the USA and European countries using the same definition of HF ${ }^{23-26}$ The reasons for the low incidence of $\mathrm{HF}$ in our population remain unknown on the basis of the present study. However, as the main etiology of HF was recognized as coronary artery disease, 1 reason might be the low prevalence of coronary artery disease in the Japanese population.$^{27-29}$ Alternatively, health-care systems differ between countries. Specifically, Japan has a universal health insurance system and most Japanese could visit medical facilities at relatively low cost. In contrast, in the USA, 15\% of persons aged under 65 years are uninsured 30 One may argue, however, that the system for capturing HF cases in the present study might have been incomplete, resulting in the underestimation of incidence. However, we did attempt to retrieve and review all medical charts or discharge summaries from cardiology and internal medicine wards of all hospitals located within the survey district. Moreover, to further reduce the potential for missing cases, the study included several remote teaching hospitals and tertiary referral medical centers located within $100 \mathrm{~km}$ of the survey area. This makes it unlikely that a significant number of HF cases would have been lost to the present registry.

Our community based study revealed significant seasonal variation in the onset of new HF as well as acute worsening of the condition. The peak in variation was seen in WinterSpring compared to Summer-Autumn. A similar seasonal variation has been reported from European countries 31 -33 Although the precise reasons for this variation remain unknown, a potential explanation might be the presence of some other condition with a well-known seasonal variation such as respiratory tract infection, myocardial infarction and ischemia, or high blood pressure. Heart rate and systemic blood pressure have been reported to rise in cold environments, thus increasing cardiac oxygen consumption and cardiac afterload. This, in turn, might increase the onset of $\mathrm{HF}$ during the Winter-Spring season in a cold climate.

Despite the advantages afforded by our community based study, several limitations must be considered when the results are interpreted. First, registration was restricted to hospitalized patients so that HF patients treated at an outpatient clinic only might be missing from the registry, resulting in an underestimation of the incidence of HF. However, physicians are less likely to treat a severe HF patient without hospitalization as the Framingham criteria used in this study tended to capture relatively advanced HF. Second, this community based study was limited to the Ninohe district, a rural area in Northeast Japan, and might therefore be restricted in its generalizability to other areas in Japan. However, other ethnicities are very rare in the Japanese population (less than 2\%), making the genetic background relatively homogeneous. Moreover, the percentage of the population aged $\geq 65$ years in the survey area is identical to the value predicted for the Japanese population in 2020. In light of this, the present study results might assist our understanding of the future epidemiological setting of HF in this country. Third, as the determination of exact etiology of HF (ie, coronary artery disease, hypertensive heart disease, valvular heart disease, cardiomyopathy, myocarditis) by non-invasive examination in an epidemiological setting has been reported to be difficult 34 we did not attempt to classify the etiology of HF in this study. Specifically, a predominantly elderly population is unlikely to be systematically examined in detail for possible coronary artery disease by coronary angiography or stress myocardial perfusion imaging. Finally, the present study did not evaluate the prognosis of $\mathrm{HF}$, and thus could not compare the prognosis for Japanese patients with HF to that of other racial populations. Further community based studies using a follow-up design would be needed to answer this question.

In conclusion, when compared with USA and European community based studies of HF, the present HF cohort has shown that: (1) mean age, prevalence of preserved ejection fraction, and seasonal variability were comparable; however, (2) the incidence rate was obviously lower. These epidemiological and clinical characteristics should be taken into consideration when establishing therapeutic and preventive strategies for $\mathrm{HF}$.

\section{Acknowledgments}

This study was supported, in part, by grant-in-aid no. 18590786 for the scientific research fund of the Ministry of Education, Science, and Culture of Japan, the Japan Arteriosclerosis Prevention Fund, and Open 
Translational Research Center Project for our University.

\section{References}

1. Ghali JK, Cooper R, Ford E. Trends in hospitalization rates for heart failure in the United States, 1973-1986: Evidence for increasing population prevalence. Arch Intern Med 1990; 150: 769-773.

2. McMurray J, McDonagh T, Morrison CE, Dargie HJ. Trends in hospitalization for heart failure in Scotland 1980-1990. Eur Heart J 1993; 14: $1158-1162$.

3. Stewart S, MacIntyre K, Capewell S, McMurray JJ. Heart failure and the aging population: An increasing burden in the $21^{\text {st }}$ century? Heart 2003; 89: 49-53.

4. Ansari M, Massie BM. Heart failure: How big is the problem? Who are the patients? What does the future hold? Am Heart J 2003; 146: $1-4$.

5. Malki Q, Sharma ND, Afzal A, Ananthsubramaniam K, Abbas A, Jacobson G, et al. Clinical presentation, hospital length of stay, and readmission rate in patients with heart failure with preserved and decreased left ventricular systolic function. Clin Cardiol 2002; 25: $149-152$.

6. Reitsma JB, Mosterd A, de Craen AJ, Koster RW, van Capelle FJ, Grobbee DE, et al. Increase in hospital admission rates for heart failure in The Netherlands, 1980-1993. Heart 1996; 76: 388-392.

7. Gooding J, Jette AM. Hospital readmissions among the elderly. J Am Geriatr Soc 1985; 33: 595-601.

8. McMurray JJV, Pfeffer MA. Heart failure. N Engl J Med 2005; 365: $1877-1889$

9. Shiba N, Watanabe J, Shinozaki T, Koseki Y, Sakuma M, Kagaya Y, et al; CHART Investigators. Analysis of chronic heart failure registry in the Tohoku district: Third year follow-up. Circ J 2004; 68: 427 434

10. McKee PA, Castelli WP, McNamara PM, Kannel WB. The natural history of congestive heart failure: The Framingham study. $N$ Engl $J$ Med 1971; 285: 1441-1446.

11. Roger JH. A significance test for cyclic trends in incidence data. Biometrika 1977; 64: 152-155.

12. Cowie MR, Fox KF, Wood DA, Metcalfe C, Thompson SG, Coats AJ, et al. Hospitalization of patients with heart failure: A populationbased study. Eur Heart J 2002; 23: 877-885.

13. Roger VL, Weston SA, Redfield MM, Hellermann-Homan JP, Killian $\mathrm{J}$, Yawn BP, et al. Trends in heart failure incidence and survival in a community-based population. JAMA 2004; 292: 344-350.

14. MacIntyre K, Capewell S, Stewart S, Chalmers JW, Boyd J, Finlayson A, et al. Evidence of improving prognosis in heart failure: Trends in case fatality in 66547 patients hospitalized between 1986 and 1995. Circulation 2000; 102: 1126-1131.

15. Koitabashi T, Inomata T, Niwano S, Nishii M, Takeuchi I, Nakano $\mathrm{H}$, et al. Paroxysmal atrial fibrillation coincident with cardiac decompensation is a predictor of poor prognosis in chronic heart failure. Circ J 2005; 69: 823-830.

16. Tsuchihashi M, Tsutsui H, Kodama K, Kasagi F, Takeshita A. Clinical characteristics and prognosis of hospitalized patients with congestive heart failure: A study in Fukuoka, Japan. Jpn Circ J 2000; 64: $953-959$.

17. Ruo B, Capra AM, Jensvold NG, Go AS. Racial variation in the prevalence of atrial fibrillation among patients with heart failure: The Epidemiology, Practice, Outcomes, and Costs of Heart Failure
(EPOCH) study. J Am Coll Cardiol 2004; 43: 429-435.

18. Vaccarino V, Gahbauer E, Kasl SV, Charpentier PA, Acampora D, Krumholz HM. Differences between African Americans and whites in the outcome of heart failure: Evidence for a greater functional decline in African Americans. Am Heart J 2002; 143: 1058-1067.

19. Afzal A, Ananthasubramaniam K, Sharma N, al-Malki Q, Ali AS, Jacobsen $\mathrm{G}$, et al. Racial differences in patients with heart failure. Clin Cardiol 1999; 22: 791-794.

20. Ohsawa M, Okayama A, Sakata K, Kato K, Itai K, Onoda T, et al. Rapid increase in estimated number of persons with atrial fibrillation in Japan: An analysis from national surveys on cardiovascular diseases in 1980, 1990 and 2000. J Epidemiol 2005; 15: 194-196.

21. Redfield MM, Jacobsen SJ, Burnett JC Jr, Mahoney DW, Bailey KR, Rodeheffer RJ. Burden of systolic and diastolic ventricular dysfunction in the community: Appreciating the scope of the heart failure epidemic. JAMA 2003; 289: 194-202.

22. Bhatia RS, Tu JV, Lee DS, Austin PC, Fang J, Haouzi A, et al. Outcome of heart failure with preserved ejection fraction in a population-based study. N Engl J Med 2006; 355: 260-269.

23. Remes J, Reunanen A, Aromaa A, Pyorala K. Incidence of heart failure in eastern Finland: A population-based surveillance Study. Eur Heart J 1992; 13: 588-593.

24. Ho KK, Pinsky JL, Kannel WB, Levy D. The epidemiology of heart failure: The Framingham Study. J Am Coll Cardiol 1993; 22: 6A$13 \mathrm{~A}$.

25. Senni M, Tribouilloy CM, Rodeheffer RJ, Jacobsen SJ, Evans JM, Bailey KR, et al. Congestive heart failure in the community: Trends in incidence and survival in a 10-year period. Arch Intern Med 1999; 159: $29-34$

26. Eriksson H, Svardsudd K, Larsson B, Ohlson LO, Tibblin G, Welin $\mathrm{L}$, et al. Risk factors for heart failure in the general population: The study of men born in 1913. Eur Heart J 1989; 10: 647-656.

27. Marmot MG. Life style and national and international trends in coronary heart disease mortality. Postgrad Med J 1984; 60: 3-8.

28. Sekikawa A, Satoh T, Hayakawa T, Ueshima H, Kuller LH. Coronary heart disease mortality among men aged $35-44$ years by prefecture in Japan in 1995-1999 compared with that among white men aged 35-44 by state in the United States in 1995-1998: Vital statistics data in recent birth cohort. Jpn Circ J 2001; 65: 887-892.

29. Menotti A, Keys A, Kromhout D, Blackburn H, Aravanis C, Bloemberg B, et al. Inter-cohort differences in coronary heart disease mortality in the 25-year follow-up of the seven countries study. Eur $J$ Epidemiol 1993; 9: 527-536.

30. Tsuda T, Aoyama H, Froom J. Primary health care in Japan and the United States. Social Sci Med 1994; 38: 489-495.

31. Boulay F, Berthier F, Sisteron O, Gendreike Y, Gibelin P. Seasonal variation in chronic heart failure hospitalizations and mortality in France. Circulation 1999; 100: 280-286.

32. Martinez-Selles M, Garcia Robles JA, Prieto L, Serrano JA, Munoz R, Frades E, et al. Annual rates of admission and seasonal variations in hospitalizations for heart failure. Eur J Heart Fail 2002; 4: 779 786.

33. Stewart S, McIntyre K, Capewell S, McMurray JJ. Heart failure in a cold climate. Seasonal variation in heart failure-related morbidity and mortality. J Am Coll Cardiol 2002; 39: 760-766.

34. Cowie MR, Wood DA, Coats AJ. Incidence and aetiology of heart failure: A population-based study. Eur Heart J 1999; 20: 421 -428. 